A $B$ I $E$ R $T$ A

\title{
DERRIDA: LA ESTRUCTURA DESPLAZADA Y EL PROBLEMA DE LA DIFFÉRANCE
}

\author{
Alejandro Sacbé Shuttera Pérez
}

Resumen: En el presente articulo se hace una lectura de la primera parte de la obra de Jacques Derrida, particularmente en el contexto de su crítica al estructuralismo y la fenomenología. El interés fundamental será tocar el tema de la diferencia, tal como lo desarrolla Derrida, para abrir algunas líneas de reflexión que puedan dar lugar a análisis de las problemáticas derridianas tanto desde la óptica de la ontología, como de la teoría del lenguaje y la filosofía política, al amparo de la influencia ejercida por Nietzsche en el filósofo francés.

Palabras clave: Derrida, diferencia, oposiciones binarias, estructura, critica de la metafísica, indecidibilidad, encadenamientos textuales, afirmación.

Alejandro Sacbé Shuttera Pérez, licenciado en filosofia por la Facultad de Filosofia y Letras de la UNAM. Maestrante en filosofía en la misma Institución, y en proceso de desarrollo del proyecto de investigación para acreditar el grado sobre temas de literatura y filosofía francesa contemporánea, correo electrónico: aletheiamx@yahoo.com.mx.
Abstract: In the present work has the purpose of undertaking a reading, of the first part of Jacques Derrida's contributions, mainly those in the context of his criticism to structuralism and phenomenology. The main concern is to address the issue of difference as Derrida develops it, to open various lines of reflection so that the derridian problematic could be analyzed not only from an ontological point of view, but also from the theory of language and political philosophy, emphasizing all the time the influence Nietssche had on the french philosopher.

Key words: Derrida, difference, binary oppositions, structure, critic of metaphysics, indecidibility, textual chains, affirmation.

L a noción de diferencia constituye un punto central en el debate filosófico contemporáneo, particularmente en lo concerniente a la escuela francesa, al implicar la puesta en cuestión de una serie de principios y valores que habitualmente han sido considerados fundamentales en la configuración de la filosofía de Occidente a lo largo de los siglos. El movimiento a partir del cual se ha desdoblado la historia de la filosofía obedece en gran medida, podríamos decir, a la interpretación y ejecución -muchas veces tácitamente- de un principio de identidad que traza gran parte de los rasgos de la fisonomía cultural occidental, desde Platón, fundamentalmente, hasta Hegel (por decirlo en términos muy generales), pasando 
por los grandes representantes de los distintos períodos (Aristóteles, Descartes, Hume), provocando así que esta historia pueda ser leída de manera relativamente unívoca y unitaria como -según estas posiciones- metafísica occidental. De acuerdo con esta lectura, sería básicamente Nietzsche la figura emblemática que rompe con el poderío metafísico de la identidad y consiguientemente pone a la diferencia en el escenario filosófico de primer plano, tendiendo con ello un puente hacia las discusiones contemporáneas. ¿Qué se entiende por “diferencia”?; ¿cuáles son sus presupuestos de interpretación?; ¿es posible, en rigor, pensarla desde nuestras premisas de racionalidad?; ¿qué consecuencias tiene para la historia de la filosofía plantearse la pregunta por el “¿que?” de la diferencia? Así, en este ensayo se intenta una aproximación, a la luz de estos problemas, a uno de los representantes más influyentes en el escenario continental contemporáneo, a saber, el filósofo francés Jacques Derrida (El Biar, Argelia, 1930-París, 2004), quizás la figura más relevante de aquello que suele ser denominado dentro de las tipologías académicas, precisamente, como filosofías de la diferencia.

\section{$* * *$}

A pesar de ser un motivo que ocupa o permea prácticamente toda la obra derridiana, el lugar paradigmático en el que Derrida aborda la problemática de la diferencia es fundamentalmente un texto titulado "La Différance", 1 pronunciado ante la Sociedad Francesa de Filosofía en 1968. El texto, uno de los más célebres del pensamiento derridiano (sobre todo de su primera época), figuraba como un auténtico manifiesto de la diferencia, parecía vindicarla como estandarte filosófico para criticar tenazmente el lenguaje de la tradición, particularmente centrando la atención en la discusión filosófica predominante en la época en torno a los alcances de la fenomenología y del estructuralismo. ${ }^{2}$
De hecho, inicialmente Derrida parecía querer ir más allá del discurso estructuralista, al cuestionar la noción misma de "estructura", pero en virtud de que su crítica se cifraba, en lo profundo, en una crítica a los postulados esenciales de la metafísica, al texto metafísico en general, la citada conferencia "La Différance" colocaba de lleno a Derrida como uno de los pensadores más audaces e influyentes en el escenario filosófico contemporáneo, y al mismo tiempo, su trabajo comenzaba a caracterizarse (y bautizarse) como "filosofía de la diferencia". 3

Derrida parte del mismo cuestionamiento nietzscheano hacia la historia de la filosofía como historia de un enmascaramiento sucesivo de los valores (o conceptos) que Occidente ha ponderado como supremos. La filosofía ha ido encubriendo su rostro característico en cada momento histórico a través de distintos nombres, y siempre bajo el auspicio de un ideal o "noción central"; ha relatado, nos dice Derrida, la historia misma de Occidente como un "encadenamiento sucesivo de distintas determinaciones del centro" (1989: 385). Derrrida entiende en este caso el concepto de centro, a su vez, situándose en la misma línea de la problematización heideggeriana sobre la noción de fundamento: la metafísica siempre ha significado por «sen» (y por tal razón lo ha mantenido en el olvido), ser de un ente, aquello que permitía asegurar la existencia del ente bajo la condición fundamental de su "estar ahí", de su ser pres-ente, a la vez como su fundamento, y a la vez como la condición de posibilidad del ente en su totalidad, esto es, en razón de su onto-teo-lógica. 'Ser", de alguna manera, era entendido como el punto de referencia y el origen de todo lo ente, aquello a lo que siempre había que remitirse puesto que "está ahí", es, en el sentido más amplio de la palabra, es decir, "la presencia del presente" (en resumen, para Heidegger, el ente supremo).

Ahora bien, esta caracterización, según Derrida, se encuentra motivada justamente por una permanente 
actitud de centralidad. La metafísica ha conformado la aparente solidez de su estructura "mediante un gesto consistente en darle un centro, en referirla a un punto de presencia, a un origen fijo..." (Derrida, 1989: 383). El ser es enviado al centro y éste funge como el punto de presencia que asegura la comprensión de los entes bajo el modo de la representabilidad, garantizando de alguna forma la coherencia de la estructura o del sistema. Cuestionar la estructura del texto metafísico es cuestionar la autoridad misma de la presencia, dirá Derrida (y así, también, cuestionar "su simple contrario simétrico", la ausencia o la falta), ${ }^{4}$ puesto que la historia de la metafísica es la historia misma de la determinación del ser como presencia, del desenvolvimiento de esa presencia; “....es la determinación del ser en presencia o en existencialidad -nos aclara- lo que es pues así interrogado, por el pensamiento de la diferencia". ${ }^{5}$ Aquí, precisamente, Derrida hace patente el explícito reconocimiento de la (aparente) proximidad entre su propuesta y la propuesta heideggeriana:

...al intentar desacreditar aquí los supuestos que nos han inducido a formar el sentido del ser en general como presencia o ausencia [...], se ve ya que el tipo de pregunta al que de este modo hemos sido reconducidos es, digamos, el tipo heideggeriano, y [nuestra noción de] diferencia parece conducirnos a la diferencia óntico-ontológica...(Derrida, 1998b: 45).

Pospongamos momentáneamente esta referencia a Heidegger. Entretanto, este formato de presencia $o$ ausencia nos lleva a uno de los aspectos esenciales que habrá de preludiar la exposición sobre la diferencia derridiana: el problema de la articulación del lenguaje filosófico como una arquitectura de oposiciones binarias (problema que siempre se mantuvo en el primer plano de su pensamiento, sino es que como su preocupación esencial). El binarismo, que desde Platón fundamentalmente se halla en la base de todo el pensamiento occidental, marca decisivamente el lenguaje filosófico no en los términos de una "coexistencia pacífica" entre dos términos, sino mediante una estructura que es esencialmente conflictual, violenta. A través de la historia de las oposiciones binarias "uno de los términos [siempre] se impone al otro (axiológicamente, lógicamente, etcétera), se encumbra" (Derrida, 1977:56) y, generalmente, en consonancia proporcional con aquella escisión "fundadora" de la filosofía entre lo inteligible y lo sensible, en la que todo lo concerniente al ámbito de este último funge como lo subordinado, como instancia dependiente y servil ante la autoridad del primero. Esta estructura constituye para Derrida un "espacio disimétrico y jerarquizante" en el que se esgrimen relaciones de fuerzas que se expulsan y rechazan hacia un "exterior" (por ejemplo, la expulsión de los artistas de la "República" platónica), y a la vez se interiorizan dentro del campo cerrado que constituye su propio sistema de dominio. El lenguaje filosófico, dice Derrida, es pues una máquina de jerarquización que constantemente produce y reproduce nuevas oposiciones, nuevas interpretaciones binarias de los conceptos. Apenas pretendemos desembarazarnos de una oposición, nos vemos envueltos en una nueva jerarquía (como en el caso de la inversión y del trabajo negativo de la dialéctica especulativa): ésta, pues, "se reconstruye siempre" (Derrida, 1997:57).

Pero ¿por qué, entonces, Derrida elige en este caso precisamente hablar de "diferencia"? ¿Qué permitiría hacernos pensar que la diferencia de la que habla no reproduce esa misma jerarquía, no confirma el orden establecido de los conceptos? Es importante señalar que para Derrida no resulta suficiente pretender criticar la metafísica por medio de una simple "puesta de cabeza" de sus valores y sus conceptos, de una mera "inversión”: “. .. a la identidad [en este caso] -nos diceno se le puede oponer otro concepto, sino un [cierto tipo de] trabajo textual" (Derrida, 1997:10-11); y, de otra 
forma: "si desde el principio no se anuncian otra lógica u otro espacio con claridad, la inversión reproduce y confirma por el lado contrario lo que ha combatido"(Derrida, 1977: 56). Entonces... ¿acaso la diferencia puede ser pensada al margen de una relación meramente binaria con respecto a la identidad?; ¿puede salir de los límites de esa oposición e inaugurar (o "anunciar") otro tipo de "lógica"? Derrida nos adelanta, por así decirlo (o anuncia) qué está entendiendo con su noción de diferencia (paulatinamente, conforme a la exposición, se irá tornando más claro):

\footnotetext{
«Diferenzia» (différance) ${ }^{6}$ designa [...] esa economía de guerra- que pone en relación a la alteridad radical o a la exterioridad absoluta de lo exterior con el campo cerrado, agonístico y jerarquizante de las oposiciones filosóficas [...]; un movimiento «productivo» $\mathrm{y}$ conflictual al que ninguna identidad, ninguna unidad, ninguna simplicidad originaria podría preceder, que ninguna dialéctica filosófica podría rehacer, resolver o apaciguar, y que desorganiza "prácticamente», «históricamente», textualmente, la oposición o la diferencia (la distinción estática) de los diferentes (Derrida, 1997: 9-12).
}

Derrida busca pensar en un orden que se mantenga irreductible ante el juego de las oposiciones binarias, y asimismo, no reproduzca su mismo esquema conceptual de dominación; “ “... es preciso dejarse llevar aquí a un orden, pues, que resista a la oposición, fundadora de la filosofía, entre lo sensible y lo inteligible" (Derrida, 1998b: 41). Pero si reconoce que tal oposición es la oposición fundadora de la filosofía, sería consiguientemente preciso entonces resistir a toda oposición, en el supuesto de que cualquier oposición esté condicionada por aquella; hablar entonces de la diferencia como si estuviera ella misma fuera de las oposiciones filosóficas. Y ello parece hacerlo, postulando una diferencia "diferente en su diferencialidad", diferente de la "diferencia" que él entiende como “distinción estática”. Pero, ¿es esto filosóficamente posible?; ¿es posible decir que la diferencia "ni es esto, ni es aquello"?; ¿cómo podríamos responder a la pregunta que interroga por el qué de la diferencia si ésta, en sentido estricto, como dirá Derrida, "no es"?7

Derrida advierte que ello constituye un análisis interminable: no se puede pensar fuera del régimen de las oposiciones que conforman la historia de la filosofía (y que han sido, prácticamente, su condición de posibilidad), puesto que - dice-, "no hay fuera de texto absoluto", "no se trata "de un linde unilineal por encima del cual podría saltarse, hacia fuera, por ejemplo hacia una «práctica» ipor fin no filosófica!. .." (Derrida, 1989: 45). Al contrario, hay que intervenir ${ }^{9}$ efectivamente dentro de ese régimen, criticar pues la filosofía, dado que "atenerse $[. .$.$] a una actitud de indiferencia neutralizante$ respecto a las oposiciones clásicas -advierte Derrida-, sería dar curso libre a las fuerzas que dominan efectiva e históricamente el campo" (Derrida, 1997: 11), y por consiguiente, significaría recaer en el orden establecido, confirmarlo.

Y esto implicaría necesariamente no quedarse en esa fase de crítica (o de inversión). Si hay que intervenir y asumir una posición comprometida dentro del trabajo filosófico, Derrida admite que entonces es necesaria también una "nueva conceptualización" (dentro y a la vez fuera de la metafísica), ${ }^{10}$ pero partiendo de una muy cuidadosa y detallada revisión del texto filosófico, ${ }^{11}$ que Derrida describe de la siguiente forma: "Hay que elaborar una estrategia de trabajo textual que a cada momento tome prestada una vieja palabra a la filosofía para a continuación de-marcarla...”(Derrida, 1977: 58).

Derrida señala aquí que se escribe "a dos manos": con una, se respeta el juego de los conceptos - "no podemos pensar si no es por medio de las oposiciones binarias" (Derrida, 1977: 60)-; y con la otra, se finge respetar, a través de una máscara (en sentido nietzscheano) por la que se le borra, se le desplaza, se le desliza "hasta su extinción y su clausura", poniendo en 
jaque la supuesta unidad de sentido que subyace a cada configuración conceptual. Dentro de esta "estrategia", nos dice Derrida, "cada concepto recibe necesariamente dos señales semejantes [...], una en el interior, la otra en el exterior del sistema [...], dando lugar a una doble lectura y a una doble escritura [...]: a una double sceance..."; 12 esto es, reconociendo las fisuras del presuntamente impecable edificio metafísico desde su interior, pero al mismo tiempo, mirando hacia afuera, hacia los bordes y los límites del sistema. Se habitan así las estructuras mismas de la metafísica, pero para revelarlas en su carácter "antiestructural"; estrategia de lo "no estratificado", "estrategia aventurada" "sin finalidad" (en el sentido de telos), estrategia en fin, que Derrida propone llamar Deconstrucción; ${ }^{13}$ En una entrevista de 1971, la define de la siguiente forma:

Deconstruir es a la vez un gesto estructuralista y antiestructuralista: ${ }^{14}$ se desmonta una edificación, un artefacto, para hacer que aparezcan sus estructuras, sus nervaduras o su esqueleto [...], pero también, simultáneamente, la precariedad ruinosa de una estructura formal que no explicaba nada, ya que no era ni un centro, ni un principio, ni una fuerza, ni siquiera la ley de los acontecimientos, en el sentido más general de esa palabra... (Derrida, 1989:48).

Y es justamente en función de esta estrategia o trabajo textual que Derrida puede perfilar su "hablar" en torno a la diferencia: toma prestada de la filosofía la palabra "diferencia" (en francés différence), y a continuación busca demarcarla mediante el gesto irónico de un "pequeño" intercambio de letras (différance); intercambio de una $e$ por una $a$, que resulta en un silencioso juego de "escribir sobre la escritura", haciéndola irreductible e indecidible (se llegará más adelante) a toda reapropiación semántica dentro de los horizontes habituales de significación (“...lo más irreductible de nuestra época”", (Derrida, 1998b: 43), llegará a decir).
Así pues, en función de todo lo anterior Derrida explica ahora por qué recurre a ese término, o qué lo impulsa a partir del tema o de la noción de "diferencia" (différance): si habla de ella, no lo hace precisamente en los términos de la inversión de una oposición tradicional, sino más bien, en los términos ("inconscientes" e "in-intencionales"), ${ }^{15}$ de una decisión "estratégica" (acorde con esa estrategia de trabajo textual). "...La diferencia (différance) - dice- me ha parecido estratégicamente lo más propio para ser pensado...” (Derrida, 1998b: 43). Y continúa: “...lo que yo propondré aquí [entonces] no se desarrollará, pues, simplemente como un discurso filosófico que opera desde un principio, unos postulados, axiomas o definiciones (puesto que lo que se pone en tela de juicio es el requerimento de un comienzo de derecho, de un punto de partida absoluto), y que se desplaza siguiendo la linealidad discursiva de un orden de razones [...] Todo en el trazado de la différance es estratégico y aventurado..." (Derrida, 1998b: 42).

Estratégico y a la vez aventurado, puesto que, dice Derrida, se trata de exceder el principio según el cual toda metodología se halla gobernada por una sucesión relativamente homogénea y ordenada de pasos, ligados entre sí, por una cierta consecución necesaria, pero al mismo tiempo desarticulando toda relación con su simple contrario simétrico, el desorden o el caos. El trazado de la différance tendría asíla forma de un juego, sostiene Derrida, de un fenómeno que simultáneamente marca su propia regla por medio de la ejecución de un "golpe de dados", y ello porque "el juego-nos explica- está más allá de esta oposición [...]; anuncia, en vísperas y más allá de la filosofia, la unidad del azar y la necesidad' (Derrida, 1998b: 42-43).

Juego de la différance, que estratégicamente se previene del cálculo de resultados, de unos objetivos delimitados y diferenciados que sirvan para administrar un orden de expectativas o modular el flujo "incesante y necesario" de su curso, de su encadenamiento textual. Juego que traza su itinerario por medio de la marca (y 
el reemplazo) de una a silenciosa que no se deja sentir como "diferente" "16 (siendo esto la regla y la condición misma del juego), pero que simultáneamente genera "efectos"17 de diferencia, haciendo cimbrar el "tímpano filosófico"18 (y el cuerpo mismo de sus enunciados) en cada movimiento y a cada tirada de dados.

Por ello, dice Derrida, este juego constituye una economía ${ }^{19}$-de guerra-que retiene el patrón jerarquizante de las oposiciones filosóficas y, a la vez, "retrasa" o impide que éstas ejerzan, tranquila y confortablemente, su función dentro del lenguaje. Y ello, gracias a ese aparentemente pequeño e inofensivo intercambio de letras en el que se conjugan paradójicamente el azar y la necesidad, esto es, gracias al movimiento (lúdico) que resulta de la "marca" gráfica de la différance. Derrida lo expresa de la siguiente forma:

Lo que se escribe como "différance" será así el movimiento de ese juego que "produce" [...] determinados efectos conceptuales [al interior del sistema de la lengua], que están a la vez impresos y fracturados por la cuña de esa "letra", por el trabajo incesante de su extraña lógica... (Derrida, 1977: 53).

Ahora bien, ese gesto mediante el que se superpone una simple letra a un concepto filosófico y que da lugar a esa "extraña lógica" y a ese extraño neografismo de la différance (Derrida lo llama una "escritura sobre la escritura") es posible en virtud de que ya se ha desplazado y subvertido el orden de la phoné, de la escritura rigurosamente fonética; “no hay phoné puramente fonética” (Derrida, 1998b: 41), afirmará él — puesto que se deconstruye la oposición misma entre habla y escritura—. ${ }^{20}$ Pero ¿cómo funciona o qué papel guarda el "signo" (la a) dentro de ese intercambio gráfico?; ¿puede por sí mismo cambiar un "significado" (el significado de la palabra "différence")? Ante esto, Derrida se propone ahora revisar algunos aspectos de esa "estructura" supuestamente primaria que es el lenguaje, a partir de un diálogo con ciertos motivos de la lingüística general de Ferdinand de Saussure (para Saussure, el lenguaje es una "facultad primaria", ya que "nos la da la naturaleza", a diferencia-dice-de muchas otras estructuras) (Saussure, 1975:25). "Partamos - nos dice Derrida-, puesto que ya estamos instalados en ella, de la problemática del signo y de la escritura [...] [con relación] a la semiología general" (Derrida, 1998b: 44-45). En este punto convendría hacer un breve recordatorio.

La lingüística saussureana guarda el aspecto de una semiología general o una teoría de los signos. El lenguaje, o mejor dicho la lengua, ${ }^{21}$ es para Saussure "un sistema de signos distintos que corresponden a ideas distintas" (Saussure, 1975: 53). Ahora bien, Derrida nos recuerda que está formado por dos cualidades correlativas: lo que Saussure llama lo arbitrario y lo diferencial del signo lingüístico. Un signo lingüístico en general se forma por la idea que representa y por el conjunto de sonidos mediante los que es enunciado, y a esto Saussure lo llama, respectivamente, el significado y el significante (signatum y signans), es decir, la parte conceptual o ideal del signo lingüístico y la imagen acústica o parte material. Ellazo, pues, que une a ambos, según él, es arbitrario y diferencial. Por ejemplo, a la palabra "gato", no le corresponden naturalmente la secuencia de sonidos "g-a-t-o"; y pronunciamos esos sonidos por no pronunciar cualesquiera otros sonidos diferentes ("rato", "pato", "dato"), ni significar con ellos cualesquiera otros contenidos mentales. Esto es, a los sonidos "gato" y "rato", que constituyen una diferencia entre significantes, les son adscritos arbitrariamente (según las convenciones de cada lengua) diferencias entre significados. Así, el lenguaje es, desde esta perspectiva, un sistema de diferencias conceptuales y de diferencias fónicas que en suma, para Derrida, se hallan relacionadas binariamente consigo mismas de acuerdo con aquella oposición "fundadora de la filosofía" entre lo inteligible y lo sensible, hacia la que Derrida convenía (como ya se hizo ver) que era preciso resistir. 
La estrategia de la différance tiende a deconstruir pues esta oposición, y para ello-según Derrida-es preciso, antes que nada, partir de un análisis semánticoetimológico aproximado "que nos lleve -dice- a la vista del juego" (Derrida, 1998b: 43), y nos indique algunos posibles sentidos de la palabra (según Derrida no es "ni concepto ni palabra" $)^{22}$ différance, tomada en la forma activa (que estrictamente no sería activa, ni tampoco pasiva, según Derrida, ya que denota cierta intransitividad como voz media) del "diferir" (en latín, diferre). El verbo diferir puede tener, de acuerdo con su raíz grecolatina, dos sentidos: uno, que es el de no ser idéntico, designar desemejanza y alteridad, y otro, que sería como la acción de dejar para más tarde, dar un rodeo, detenerse brevemente en el tiempo, hacer demorar por una economía de reserva. Derrida conjuga y correlaciona ambos sentidos para crear así dos tipos de neologismos (o encadenamientos textuales): el "diferir", entendido como ese movimiento de rodeo que retarda la aparición del presente en virtud de una especie de "mediación temporal", es denominado como temporización; y, por otra parte, el "diferir" como alteridad o desigualdad, que supone a su vez que entre los elementos "otros" - mantenidos respectivamente en relación-exista un cierto intervalo, una cierta distancia de separación, Derrida lo designa mediante el término espaciamiento; "...temporización y espaciamiento [...], extraña economía de hacerse tiempo del espacio y hacerse espacio del tiempo, 'constitución originaria' del tiempo y del espacio" (Derrida: 1998b: 43). Cabe notar la forma en la que Derrida, parodiándolo, hace uso del lenguaje de la metafísica y de la fenomenología trascendental.

Ahora bien, este pasar por el rodeo al elemento presente tiene lugar justamente en virtud de la extensión de un intervalo que lo relaciona con su "ser otro" y que lo hace ser lo que es, constituirse a sí mismo como presente (por ejemplo, "es", gracias a que se distingue de aquello que "no es") reteniendo simultáneamente su aparición (presente ya pasado), y anunciándose en el trayecto inconmensurable de su ser-otro (presente aún por-venir): el presente así se desliza, se barre hacia esa marca en la que deviene "otra" cosa y ya no mero presente, ya que al temporizar, al espaciar "ha de ser pasado y al mismo tiempo ha de ser futuro" (Derrida, 1998b: 48). Años más tarde Derrida describe, en sus Espectros de Marx, aquello en lo que podría consistir este efecto "espacio-temporizador" de la différance, a la que equiparará (relativamente) con la noción de "espectralidad":

Si hay algo como la espectralidad -inquiere-, hay razones para dudar de este tranquilizador orden de los presentes, y sobre todo de la frontera entre el presente, la realidad actual o presente del presente, $\mathrm{y}$ todo lo que se le puede oponer: la ausencia, la nopresencia, la inefectividad, la inactualidad, la virtualidad en general, etc. [...] [Se trata pues de] (interrogarse acerca de si es posible) desbaratar esta oposición, incluso esta dialéctica, entre la presencia efectiva y su otro (Derrida, 1995: 52-53).

En virtud de todo esto, y aterrizando el empleo de estos términos, se podría, en cierta forma, advertir el análisis y el desglose hechos por Derrida a los postulados de la lingüística estructural.

Diferir como temporización tiene lugar dentro del movimiento de la significación como un pasar por el rodeo a la cosa misma, es decir, representar lo presente en su ausencia por medio del signo, retardar su aparición: “...cuando no podemos tomar o mostrar la cosa, digamos lo presente, el ser presente [...], significamos, pasamos por el rodeo del signo" (Derrida, 1998b: 45). El signo sería pues, según Derrida, "la presencia diferida". Ahora bien, de acuerdo con la caracterización clásica de la semiótica estructural el signo sería, en efecto, como una especie de sustituto puesto ahí en representación de la presencia pura, pero que requiere, para ser pensado, de la efectiva presentación de lo presente, es decir, que el significado coincida con el 
significante. "El signo lingüístico - dice Saussure- es una entidad psíquica de dos caras [...] que están intimamente unidas y se reclaman recíprocamente..." (Saussure, 1975: 129). El diferir como espaciamiento, por su parte, impide esa conjunción, ya que el significante no puede considerarse propiamente como correlativo a su significado. En suma, desde la base del planteamiento de la différance la relación se rompe, se disloca, no constituye ya algo propiamente simétrico, puesto que "el significado -afirma Derrida- está ya siempre en posición de significante” (Derrida, 1977: 77), y ello, en gran parte, dado que a su vez no puede haber lo que Derrida llama un "significado trascendental". ${ }^{23}$ ¿Qué quiere decir esto?; ¿qué implicaciones trae consigo? Intentemos resumirlo brevemente.

Cuando se intenta definir un significante, la remisión del significado al lenguaje produce que él mismo se vuelva significante, $y$ al intentar significarse éste, a su vez, significante de otro significante, difiriéndose el movimiento de la significación ad infinitum, en puros significantes significando significantes. Pero por otro lado, como consecuencia de esto, no se puede, asimismo, partir de un significante vacío, puro, desprovisto de lo inteligible, destaca Derrida, puesto que por sí mismo guarda un papel en el lenguaje en el que "debe" evocar algo, referir a algo, en suma, sersignificado. Así, por lo anterior, si admitimos entonces que no existen significados primarios que no sean a su vez significantes -lo que equivale propiamente a que no hay significados , no hay, por ende, significantes, del mismo modo como no puede haber un reverso sin un anverso de una hoja: siempre se remiten simétricamente el uno al otro y viceversa. De este modo, tras haberse deconstruido la primacía de la relación significante-significado en el lenguaje, pareciera que lo único que nos queda es el signo, con lo que hay que partir en la significación (" ... en cuanto al término signo — dice Saussure_- si nos contentamos con él, es porque no sabemos con qué reemplazarlo...") (Saussure, 1975: 130). Sin embargo, al resaltar a su vez Derrida que el signo no es más que algo puesto en representación de algo presente, necesariamente, ha de convertirse en una instancia secundaria, tardía, inauténtica, no originaria; así lo manifiesta Amalia Quevedo en su interpretación de Derrida: "Un origen secundario ni es origen ni es secundario. De modo que no hay origen, ni principio, ni cosa, ni signo" (Quevedo, 2001: 57). Derrida explica el asunto del siguiente modo:

$$
\begin{aligned}
& \text { El juego de las diferencias supone, en efecto, síntesis } \\
& \text { y remisiones que prohíben que en ningún momento, } \\
& \text { en ningún sentido, un elemento simple esté presente } \\
& \text { en sí mismo y no remita más que a sí mismo. Ya sea } \\
& \text { en el discurso hablado o en el discurso escrito, ningún } \\
& \text { elemento puede funcionar como signo sin remitir a } \\
& \text { otro elemento que tampoco él mismo está simple- } \\
& \text { mente presente. Este encadenamiento hace que cada } \\
& \text { "elemento" -fonema o grafema- se constituya a } \\
& \text { partir de la "huella" que han dejado en él otros } \\
& \text { elementos de la cadena o del sistema. [...] No hay } \\
& \text { nada, ni en los elementos ni en el sistema, } \\
& \text { simplemente presente o ausente. No hay, de parte a } \\
& \text { parte, más que diferencias y trazas de trazas (Derrida, } \\
& \text { 1977: 69-70). }
\end{aligned}
$$

Trazas, huellas o marcas. ¿De dónde surgen estos términos? Derrida advierte que el juego de la différance es un "movimiento productivo". La différance no es en sí misma "ni una palabra, ni un concepto", 24 pero ello no le impide — dice- producir, crear efectos conceptuales, efectos "de diferencia" al interior de la lengua, esto es, términos que "hacen diferencia" y que por sí mismos no podrían ser ya considerados signos, entendiendo por ello la transparente unidad de un fenómeno que reúne dentro de sí la convergencia simétrica de un significante y un significado. Pero por su parte, subraya Derrida, este "producir" diferencias al interior de la lengua, no implica necesariamente que haya que responder a las preguntas “¿qué difiere?” o 
“¿quién difiere?”. La différance no puede considerarse como el fundamento (en sentido metafísico) de estas diferencias o, más explícitamente, como el origen, dado que ello implicaría admitir la existencia de un "algo" que funge como un significado trascendental, o un punto de presencia estable desde el que "alguien" produce estos efectos diferenciales, gozando de una cierta autonomía contextual que escapa a los linderos del juego (clausura de la subjetividad); “...el nombre de 'origen', pues — dice Derrida_, ya no le conviene" (Derrida, 1998b: 47). De modo que, consiguientemente, la différance no "causa" las diferencias, no produce las diferencias como entidades causadas, lo que, en sentido estricto, conduciría a no hablar más de efectos (y por ende, de "efectos de diferencia"), bajo el supuesto de que la relación causaefecto se encuentra dispuesta según la lógica de las oposiciones binarias. Por ello, explica, "a la salida fuera de este esquema he tratado de indicar[lo] mediante lo que designaré [como] la 'marca', [(o la 'huella' o 'traza' diferencial)]...”(Derrida, 1998b: 47).

Así, dado que no hay origen, ni un punto de anclaje que garantice la apertura o la puesta en marcha de esa economía productiva de las diferencias, nos encontramos necesariamente en una cadena que está constantemente difiriéndose a sí misma desde la óptica de la différance. No se está tratando con un elemento que esté en sí mismo, simplemente, presente al interior del sistema lingüístico, ni con una supuesta reminiscencia del presente, sino con una marca que se inscribe sediciosamente en la lengua y se retrotrae hacia sus límites (o hacia sus bordes), borrándose simultáneamente al tiempo en que es "alcanzada" por una presencia, es decir, desapareciendo "en el momento en que trata de aparecer” (Derrida, 1998b: 59); “.... siempre difiriendo, la marca no está nunca como tal en presentación de sí. Ella se borra al presentarse, se hace sorda resonando, como la $a$ al escribirse, inscribiendo su pirámide en la différance" (Derrida, 1998b: 57).
El juego de la marca simula y disloca los horizontes mismos de la presencia, los obnubila y confunde (como el "fantasma" de Hamlet). ${ }^{25}$ En el momento en que la marca intenta ser nombrada, puesta en operación, difiere, desaparece y se desplaza hacia el borrarse mismo de lo que marca, pone a la presencia completamente desquiciada -out of joint-, la hace "salir de sí en su posición", se desliza "hacia su extinción y su clausura". Y así también, dicha marca se extingue, según Derrida, "no tiene sentido" y "no existe", ${ }^{26}$ pero, no obstante, transgrede el espacio que habita el texto metafísico, puesto que se deja escribir y reinsertar en él, alterizándose y transformándose continuamente en algo siempre diferente. Es, pues, la marca misma de la différance, la (resultante de la) a silenciosa, que únicamente se "hace oír", se "hace presente" podríamos decir, en la medida de su transformación en otro texto. "... operar [en el texto metafísico] una especie de desplazamiento a la vez ínfimo y radical" (Derrida, 1998b: 50). Derrida dirá más tarde, con respecto a esto:

...los efectos [de la différance] no sólo se vuelven sobre ellos mismos por una especie de auto-afección sin apertura, sino que se propagan en cadena sobre el conjunto práctico y teórico de un texto cada vez diferente... (Derrida, 1989:56).

Así pues, si la différance no puede quedar comprendida en la habitual lógica de significación, es porque pone en operación un conjunto de marcas que "se propagan en cadena" unas a otras y entre sí, alrededor y dentro de los márgenes de esa misma lógica, produciendo insistentemente nuevas series o encadenamientos textuales. "Otro [tipo de] texto". Escribir de otra manera, planteaba Derrida, jugar con el movimiento de la significación, avistar la experiencia de un lenguaje sin signos, ${ }^{27}$ de trazas sobre trazas: marcas que constantemente se superponen unas a otras en una cadena irreductiblemente abierta que desorganiza, invade y disloca sin cesar el orden de las 
oposiciones filosóficas. Y aquí es donde puede plantearse la cuestión de la "indecidibilidad", o lo que Derrida llama la "cadena de los indecidibles": "...unidades de simulacro, 'falsas' propiedades verbales, nominales o semánticas, que ya no se dejan comprender en la oposición filosófica (binaria) y que no obstante la habitan, la resisten, la desorganizan, pero sin constituir nunca un tercer término, sin dar lugar nunca a una 'solución' en la forma de la dialéctica especulativa". 28

La différance, pues, hace posible de alguna forma la propagación de esta cadena, de estos términos indecidibles (Derrida la llama una "superestructura originaria"); ${ }^{29}$ pero ella misma es un indecidible y es indecidible. Y esto en dos sentidos: por una parte, la différance es aquello que permite el abrirse de la cadena diferencial, pero al estar permanentemente difiriéndose a sí misma, no puede escapar a su juego, se halla necesariamente inscrita en ella -jamás precede a los mismos efectos diferenciales que produce- $y$, en tal medida, es un indecidible más (se podría en todo caso hablar de un coorigen, lo que hace a Derrida enfatizar que la différance no puede conllevar ningún tipo de reminiscencia teológica). Y por otra parte, en virtud de ello mismo, la différance es indecidible en el específico dominio al que alude dentro del lenguaje metafísico (diferencia): rompe el procedimiento lógico por el cual la diferencia permanece necesariamente resguardada como un término subordinado al principio de identidad (como diferencia entre...), y a la vez rompe la oposición identidad/diferencia, no siendo "ni lo uno" "ni lo otro" (pero sin constituir nunca un tercer término).

La diferencia es pensada, pues, lejos completamente de toda oposición (como ha venido insistiéndose), permanece indiferente ante ellas: “....En cuanto a la différance [...], estas oposiciones no tienen la más mínima pertinencia...” (Derrida, 1998b: 52); y, en tal medida (regresando a lo anotado en páginas anteriores), podría relacionarse muy próximamente con aquella consigna heideggeriana de pensar la diferencia en cuanto diferencia. ${ }^{30}$ Derrida lo reconoce, tanto en el comentario que ya citamos como cuando dice que entre el motivo de la différance, con respecto al texto heideggeriano, "la comunicación es estrecha, incluso si no es exhaustiva e irreductiblemente necesaria" (Heidegger, 1990: 46).

Sin embargo, Derrida tendrá reservas con respecto a Heidegger y su misma noción de diferencia ontológica. Las últimas páginas de la conferencia sobre "La Différance" tendrán como motivo ese "diálogo necesario" con Heidegger; en ellas, Derrida tomará explícitamente distancia al subrayar que la estrategia de la différance no busca, "como pretendía Heidegger", la posibilidad de un lenguaje distinto basado en la recuperación y en la rememoración de la diferencia ontológica, que nos "libere" del yugo de la presencia y del pensar metafísico. Y ello, sobre todo, a partir de la lectura de un texto de Heidegger titulado "La sentencia de Anaximandro" (Heidegger, 2000), en donde éste escribe, a modo de conclusión: "el ser habla en todas partes y siempre y a través de toda lengua" (Derrida, 1998b: 62). Derrida considera que esta visión es aún presa de cierta "nostalgia metafísica" y la designa como la esperanza heideggeriana. Él, en efecto, al afirmar que la différance "no tiene ningún nombre en nuestra lengua", se estaría refiriendo a que auténticamente es un innombrable: no hay lengua posible, ni dentro ni fuera del horizonte metafísico, ya que es un juego nominalmente dislocado y es el juego que pone en cuestión el nombre mismo de nombre. La différance no tiene nombre, no tiene origen ni fin y sólo marca, pues, disolviéndose en su propia marca. Por ello, no esperemos, dice Derrida, la "puesta a la luz" de la originaria pertenencia de la palabra al ser, "la búsqueda de la palabra propia y del nombre único" (Derrida, 1998b: 62). Es necesario pensar la diferencia (la différance), antes que nada, sin nostalgia para poder hacerle frente, para poder hacer frente - como sugería el mismo Heidegger — al "enigma del pensar"; es preciso, pues, desistir de la esperanza que evoca la "patria perdida del pensamiento" y por el contrario — y aquí es donde Derrida radicaliza su 
toma de distancia hacia Heidegger-, si habría de ser asumida una "actitud" respecto al pensamiento de la différance, de la diferencia, el gesto correspondiente sería el de la afirmación, y la herencia o el testimonio de la différance nos conduciría así inevitablemente a Nietzsche.

...Para [un pensamiento como el de] la différance, no basta con quedarse en [la negatividad que implica] la imposibilidad (metafísica) de un "nombre" [...] Al contrario, [a ésta] es preciso [más bien] afirmarla, en el sentido de la afirmación nietzscheana [...]: la afirmación gozosa del juego del mundo y de la inocencia del devenir [...]; [afirmarla] en el azar absoluto..., con una risa y un paso de danza...(Derrida, 1986b:62). ${ }^{31}$

Y, ya para concluir -y apoyar esto-, podría quizás ser interesante citar una frase que el mismo Derrida pronunció en la última entrevista que concedió antes de morir, que podría considerarse como una especie de diagnóstico general acerca de su propio trabajo filosófico, además de un lúcido reconocimiento casi póstumo hacia Nietzsche: “...todo el tiempo la deconstrucción está (y ha estado) del lado del sí, de la afirmación de la vida..." (Birnbaum, 2004).

\section{Notas}

${ }^{1}$ Aparecido inicialmente en Theorie d'ensemble, col. Quel, Ed. Seuil, en 1968, y posteriormente en Marges de la philosophie (Márgenes de la filosofía), en 1971.

2 La conferencia sobre "La Différance", de alguna forma, condensaba críticas a ambas, concentrándose tanto en el estructuralismo y la lingüística saussureana y, un poco menos, en la fenomenología. No obstante, ya antes de ese texto Derrida se había ocupado sustancialmente de la fenomenología y el estructuralismo en sus primeras obras, en concreto con Lavoz. y el fenómeno (1967) y De la gramatología (1967), respectivamente. Cabría también mencionar, antes de éstas, la conferencia "La estructura, el signo y el juego en el discurso de las ciencias humanas" (aparecida posteriormente en La escritura y la diferencia), que Derrida pronunció en 1966 en la Universidad
Johns Hopkins, en Estados Unidos, la que, en virtud de su crítica al estructuralismo, valió a Derrida el título de pensador "postestructuralista", título que aún hoy sigue detentando en muchas clasificaciones académicas. Como testimonio, podría ser interesante citar las palabras de Frank Lentrichia, asistente a dicho encuentro, quien confiesa: “...En esa [conferencia] nos despertamos del sopor dogmático de nuestro sueño fenomenológico para darnos cuenta de que una nueva presencia se había asentado en nuestra imaginación crítica de vanguardia: Jacques Derrida. Con cierta brusquedad supimos que, a pesar de una buena suma de caracterizaciones inconexas de lo contrario, nos trajo, no el estructuralismo, sino algo que podría llamarse «post-estructuralismo»..." (Culler, 1992). Derrida, por su parte, asume que esa caracterización es típicamente americana e insuficiente, y rehúye un tanto a ella. En "Carta a un amigo japonés”, escribe: “...en Estados Unidos se ha asociado el motivo de la deconstrucción al «post-estructuralismo»...", y después, afirma: "[No obstante] esa palabra es desconocida en Francia, salvo [únicamente] cuando «vuelve» de Estados Unidos [...] y no es [precisamente] una palabra afortunada...", en El tiempo de una tesis: Deconstrucción e implicaciones conceptuales, Proyecto A Ediciones, Barcelona, 1997: 25-26.

${ }^{3}$ En esta empresa, Derrida suele ser asociado a pensadores como Foucault, Deleuze, Lyotard, entre otros. Sin embargo, sería difícil explícitamente reducirlos a ser "pensadores de la diferencia", sin más, dado que todos ellos son fundamentalmente reticentes a ocupar un lugar dentro de un estante filosófico o una "corriente" homogénea dentro de la historia de las ideas. Deleuze, por ejemplo, dice: “. ..La historia de la filosofía siempre ha sido el agente de poder dentro de la filosofía, e incluso dentro del pensamiento... ¿cómo queréis pensar fuera de tal o cual 'corriente' en particular?..." (Deleuze, 1997: 17). Finalmente, los demás podrían decir lo mismo, quizás, con otras palabras.

${ }^{4}$ Derrida (1989: 400) señala que, en rigor, "hay que pensar antes de la alternativa de la presencia y de la ausencia [...]; cuestionar su autoridad..."

${ }^{5}$ (Derrida, 1998b: 43). A esa determinación histórica del ser en presencia Derrida le llamará, siguiendo la misma línea de Heidegger, una "metafísica de la presencia". Haciendo un breve repaso sobre esas distintas determinaciones, Derrida escribe: “...presencia de la cosa para la mirada como eidos, presencia como substancia/esencia/existencia (ousía), presencia temporal como punta (stigme) del ahora o del instante (nun), presencia en sí del cogito, conciencia, subjetividad, copresencia del otro y de sí mismo, intersubjetividad como fenómeno intencional del ego, etc. [En suma] la metafísica sería, por 
lo tanto, solidaria de la determinación del ser del ente como presencia" (Derrida, 1971: 22-23).

${ }^{6}$ Derrida intercambia, en la palabra francesa original différence, la segunda $e$ por una $a$ (más adelante se explicará por qué razones). Muchos traductores han llevado por consiguiente este neologismo (o "neografismo") derridiano al castellano de diversas formas. Aparte de este caso «Diferenzia», se ha traducido también «Diferancia», «Diferiencia», entre algunas otras.

${ }^{7}$ Derrida reconoce que los motivos sobre los que se articula o se "borda" la exposición acerca de la différance, podrían llegar a confundirse con los principios de la llamada "teología negativa", puesto que la différance, como dice, al ser tan irreductible a las categorías de nuestro lenguaje, parece únicamente permitir que se hable de ella como diciendo lo que no es, como señalando negativamente sus atributos, al modo del Dios al que se le niega la existencia para reconocerle "un modo de ser superior, inefable". Derrida insistirá en que "no se trata aquí de un movimiento asî". La différance, dirá, "se encuentra presa en un trabajo que arrastra a través de una cadena de otros «conceptos», de otras «palabras»..." (Derrida, 1977: 76), las cuales codeterminan su propia posibilidad. Por ello, es incapaz de instituirse en una "palabra maestra" o en un "concepto maestro", cuya exposición dé lugar a reminiscencias teológicas "ni siquiera en el orden más negativo de la teología negativa" (Derrida, 1998b: 42).

${ }^{8}$ En el original francés Derrida escribe "Il n y a pas de horstexte", que comúnmente se traduce por "no hay nada fuerade-texto". Según Jonathan Culler, esa traducción es bastante engañosa, puesto que "...Derrida no redujo todo al lenguaje, como una especie de ultra-idealista que concibe al 'fuera' como lo inexistente. En realidad él escribió: 'No hay texto-exterior', [y con ello] más bien estaba diciendo que una vez que uno ve al lenguaje como un movimiento constante de diferencias en el que no hay ningún punto de descanso estable, ya no se puede apelar a la realidad como un refugio independiente del lenguaje. Todo adquiere la inestabilidad y la ambigüedad que Derrida planteaba que era algo inherente al lenguaje” (Culler, 1992: 115).

${ }^{9}$ A Derrida le preocupaba grandemente la cuestión de una "toma de partido" en la filosofía y, según sus mismas declaraciones, desde sus primeros textos. Sin embargo, muchos consideraron que en ellos no se reflejaba una toma de partido clara, particularmente en lo concerniente al análisis sobre la historia y la política ( $C f r$. por ejemplo, el diálogo con Jean-Louis Houdebine, y la carta enviada por éste a Derrida, en Posiciones: 85-91 y 120-124). No es sino hasta un texto de 1993 titulado
Espectros de Marx, que comienza a verse en Derrida un pensador genuinamente preocupado por problemas políticos. De hecho, entre toda su extensa obra, se considera este texto su declaración más claramente política (sin despegarse en ningún momento de la filosofía). En él, por ejemplo, Derrida escribe: “....no hay ningún gusto por el vacío o por la destrucción en quien satisface esta necesidad de 'vaciar' continuamente y de deconstruir respuestas filosóficas que consisten en totalizar, en llenar el espacio de la cuestión o en denegar su posibilidad. Por el contrario, se trata aquí de un imperativo ético y político, de una llamada tan incondicional como la del pensamiento del que no se separa..." (Derrida, 1995: 44). En el texto se pueden encontrar muchas más alusiones referidas a esto.

${ }^{10}$ Se puede decir que Derrida caracteriza ese espacio o esa lógica en la que se trabajan los conceptos de la metafísica, como una "lógica ex-cursiva", que siempre está moviéndose ni en el afuera, ni en el adentro del texto filosófico, sino en su "entre". Mónica Cragnolini sugiere, con respecto a esto: "...La lógica 'ex-cursiva' derridiana sale del curso y nos coloca en el ámbito de una lógica paradójica [...]; no es un nuevo lugar, sino que es no-lugar, imposibilidad de asentamiento, constante peligro, no presencia, 'quizás' nietzscheano...", "Un mundo de fantasmas y huellas sin origen", artículo aparecido en La Nación (revista), octubre de 2004, www.personales.ciudad.com.ar.

${ }^{11}$ Derrida tiene perfectamente presentes los riesgos que conlleva toda "nueva" iniciativa de elaboración conceptual, y es bastante claro en este sentido: “. .. la conceptuación misma, y ella sola (hay que darse bien cuenta de esto) [...], puede reintroducir lo que se quería criticar" (Derrida, 1977: 77).

${ }^{12}$ (Derrida, 1997: 8). Este texto está integrado por tres largos ensayos (además de un importante "pre-facio"), de los cuales el segundo justamente se titula "La doble sesión" (La double sceance), dedicado fundamentalmente a una lectura del Mimique, de Mallarmé. El texto había tenido lugar en dos sesiones entre el 26 de febrero y el 5 de marzo de 1969, e inicialmente figuraba sin título. La redacción de la revista Tel Quel, que fue donde apareció por primera vez, supuestamente proponía el título por esa simple razón de que había sido presentado en dos sesiones. Paradójicamente, Derrida retomará las implicaciones semánticas de dicho título, para ilustrar el modo en el que se lleva a cabo su trabajo textual, justamente, como un trabajo "doble". Se expondrá brevemente esto un poco más adelante.

${ }^{13}$ El término "Deconstrucción", uno de los más importantes de la filosofía derridiana, e incluso mediante el que común- 
mente se llega a caracterizar su trabajo, ha dado lugar según Derrida a muchas ambigüedades y muchos malentendidos. En "Carta a un amigo japonés", (Derrida, 1997: 23-27), el autor, a propósito de comentar la posibilidad de traducir "deconstrucción" al idioma japonés, busca esclarecer algunos de ellos. En primer lugar, afirma retomar el término un tanto por inspiración heideggeriana, conjuntando los vocablos alemanes Destruktion y Abbau, los que, dice, "deseaba traducir y adoptar a mi propósito" (Derrida, 1997: 23). El término francés para "destrucción", confiesa Derrida haberlo "descartado" dado que era de una connotación demasiado negativa, próxima, dice, a la "demolición nietzscheana”, y por el contrario, afirma Derrida, “...Más que destruir era preciso asimismo comprender cómo se había construido un 'conjunto' y para ello, era preciso reconstruirlo" (Derrida, 1997: 26). "Deconstrucción", apoyándose en el Littre (Diccionario de la lengua francesa), le permitía de alguna manera sugerir esto. Por otra parte, la deconstrucción -aclara-no es ni un "análisis", ni una "crítica", ni, sobre todo, un "método" (Derrida, 1997:26), es completamente indefinible e intraducible y no se deja llevar a ningún orden lógico de significaciones. Tanto ese orden como esos "valores" - dice-, son "filosofemas sometidos a la deconstrucción” (Derrida, 1997: 26). De un modo relativamente parecido al caso de la différance, Derrida admite la posibilidad de encontrarse en ello una especie de teología negativa: “... ¿lo que la deconstrucción no es? ¡Pues todo! ¿Lo que la deconstrucción es? ¡Pues nada!” (Derrida, 1997: 27). Pero si la deconstrucción -y en eso pone el énfasis-no puede "ser", en el sentido más llano de la palabra, es porque designa un "acontecimiento" que siempre está teniendo lugar, cada vez, de modo singular, desde un "contexto", un "idioma" o una "firma", fuera de los cuales es absolutamente imposible (se halla necesariamente inscrito dentro de una cadena) "...por sí sola-dice-no me ha parecido nunca una palabra satisfactoria [...] debe estar siempre rodeada de un discurso..." (Derrida, 1997: 27). Por ello, tampoco es una palabra precisamente "afortunada". Derrida se lamenta de que incluso se hayan revertido las intenciones iniciales por medio de las cuales fue concebida, llegándose a convertir incluso en una especie de moda filosófica. "Cuando elegí esta palabra... jamás pensé que se le fuera a reconocer un papel tan central en el discurso..." (Derrida, 1997: 23). Y ello, no sin cierta ironía, dado que esa centralidad discursiva era la que Derrida se proponía asimismo criticar o, precisamente, “deconstruir". Para una revisión más detallada, aparte de la citada fuente, cfr. La deconstrucción en las fronteras de la filosofía, Paidós, Barcelona, 1998.
${ }^{14}$ Como ya se dijo, la palabra deconstrucción nace exclusivamente bajo el contexto del dominio teórico del estructuralismo. Y en cierto sentido debe entenderse teniendo siempre en cuenta la problemática de la "estructura", que no necesariamente se reduce a la corriente llamada estructuralismo, sino que puede extenderse en general a todo lo que puede ser llamado metafísica occidental, cfr. "La estructura, el signo y el juego...

${ }^{15}$ Derrida tiene presente aquí la crítica a los postulados de la fenomenología trascendental.

${ }^{16}$ La diferencia entre la $e$ y la $a$, dice Derrida, "no se oye, permanece silenciosa y discreta" (habrá que recordar que Derrida estaba dictando una conferencia ante un foro, "haciéndose oír"); no hay ninguna diferencia entre las palabras différence (la original, en francés), y différance, puesto que suenan igual, se pronuncian igual, es decir, la diferencialidad que constituía el signo, permitía a Derrida ejemplificar que éste no era a su vez algo aferrable como "diferente".

${ }^{17}$ Derrida, al postular ese movimiento de la différance tenía en la mira fundamentalmente romper con la lógica del discurso filosófico occidental y sus principales categorías. Era un término que daba lugar a ciertas caracterizaciones del tipo de la teología negativa -como ya vimos-, puesto que se resistía a ser definido o reasumido en un esquema unitario. Si no se podía definir era porque fundamentalmente su movimiento escapa a la representación de un origen o un punto de partida semánticamente estable; en otras palabras, su origen se encuentra siempre "diferido". Pero asimismo reconoce, junto con el lingüista Ferdinand de Saussure (más adelante llegaremos a eso) que la différance, así como el sistema de las diferencias lingüísticas, no han, como dice este último, "caído del cielo", son (en un cierto sentido) "históricas" de parte a parte. Y aquí se encuentra una aparente dificultad: si las diferencias no tienen origen puesto que están ya siempre diferidas, parecería que no son más que efectos al interior de la lengua (u otro determinado sistema o estructura), pero ello inevitablemente nos conduciría a la relación del efecto con una causa, que a su vez haya sido la encargada de producirlo y así, nuevamente, a la noción de origen, (y por ende a un determinado binarismo). De ahí que Derrida recurra sobre todo a la noción de "huella" o "marca" (más adelante se tratará ese punto). Sin embargo, en textos posteriores, no abandona completamente el hablar de "efectos" (ni siquiera totalmente en el mencionado "La Différance"), y utiliza esa noción, por así decirlo, en un cierto sentido "convencional". Derrida por ejemplo escribe: “... [Algunos de] estos términos [(el caso de la noción de "efecto")] se deben entender más allá de la lengua 
metafísica en la que se han trazado con todas sus implicaciones $[\ldots]$ y yo no los uso aquí, como muchos otros conceptos, sino por comodidad estratégica y para iniciar la deconstrucción de su sistema en el punto actualmente más decisivo..." (Derrida, 1998b: 48).

18 "Tímpano", es el título del primer ensayo de Márgenes de la filosofía, y en él, Derrida juega un tanto con su sentido, teniendo presente esta relación paradójica entre la escritura que "no se puede oír", en términos fonéticos, y los efectos que ésta produce en el "oído filosófico" ("...esto no se puede escribir sin una deformación del tímpano filosófico..." (Derrida, 1998c: 21). Tympaniser, según el texto, tiene la doble significación de ser un elemento auditivo, que se aúna con el recuerdo de lo "sonoro", y también, la de conllevar un sentido emparentado con "criticar", "anunciar a bombo y platillo", "golpear" o "percutir". Derrida escribe: "Sabemos que la membrana del tímpano [es] un tabique delgado y transparente $[\ldots]$, pero ¿podemos penetrar violentamente su campo de escucha sin que al punto, fingiendo incluso la ventaja, la filosofía, si escuchamos lo que se dice de ella, si decodificamos el enunciado, lo haga resonar en ella, se apropie de su emisión? [...] Dicho de otro modo, ¿'se puede hacer estallar el tímpano de un filósofo y continuar haciéndose oír por él?” (Derrida, 1998c: 19).

${ }^{19}$ Derrida lo concebía en los términos de una "economía general sin reserva”, sobre el que decía era uno de los puntos de mayor oscuridad en la exposición sobre la différance (cfr. Derrida, 1998b: 54). Derrida menciona, con respecto a esta economía de la différance: “...una economía general que toma en consideración la no reserva. Relación entre una différance que encuentra su cuenta y una différance que fracasa en encontrar su cuenta, la apuesta de la presencia pura y sin pérdida confundiéndose con la de la pérdida absoluta, de la muerte..." (Derrida, 1998: 55). La idea sobre esta "economía general", sobre todo le vino a partir de un diálogo o confrontación entre distintos motivos del pensamiento de Hegel con el de Bataille. Cfr. "De la economía restringida a la economía general. Un hegelianismo sin reserva", en $L a$ escritura y la diferencia.

${ }^{20}$ La escritura, cabe mencionar, es uno de los conceptos clave y más complejos de Derrida (prácticamente de la misma importancia que el concepto de différance). Desde sus primeros textos, Derrida se había propuesto deconstruir la relación binaria que la escritura siempre había mantenido con respecto al habla, preocupación que daría lugar, incluso, al proyecto de una "teoría general sobre la escritura", sobre una escritura no-fonética, llamada así por Derrida como Gramatología. Cfr. De la gramatología, sobre todo Cap. I, "El fin del libro y el comienzo de la escritura".

${ }^{21}$ Según Saussure, la lengua no se confunde con el lenguaje, no es más que "una sola de sus manifestaciones, aunque esencial". El lenguaje es "multiforme y heteróclito [...] no se deja clasificar en ninguna de las categorías de los hechos humanos", en tanto que la lengua "por el contrario, es una totalidad en sí y un principio de clasificación” (Saussure, 1975: 50-51).

${ }^{22} \mathrm{La}$ différance no es, según Derrida, ni una palabra, es decir "lo que se representa como una unidad tranquila y presente, autorreferente, de un concepto y de una fonía", ni un concepto, puesto que, dirá, es "la posibilidad misma de la conceptualidad” (Derrida, 1998: 45-46). Esto último, se precisará más conforme la exposición.

${ }^{23}$ Derrida, por ejemplo, declara: “...No hay un significado trascendental, puesto que no hay [ningún] significado que escape, para caer eventualmente en él, al juego de referencias significantes que constituye el lenguaje [...] En él el significado funciona como un significante desde siempre." (Derrida, 1971: 12).

${ }^{24}$ Cfr. nota 22.

${ }^{25}$ El texto sobre los Espectros de Marx, sobre todo en su primer capítulo, está en gran parte motivado por una lectura del Hamlet, de Shakespeare; incluso comienza citando una frase de Hamlet en la que éste parece concentrarse en el arribo de un "fantasma", el fantasma de su padre, que ha "descontrolado" y “desajustado" la situación política (y temporal) en Dinamarca. Una de las frases más persistentes de Hamlet y que a Derrida le parece sumamente significativa y problemática, es The time is out of joint, frase que Hamlet enuncia fundamentalmente para indicar que el tiempo o la situación presente está, por así decirlo, "fuera de lugar". "Time” en este contexto puede designar a la vez varias lecturas (Derrida las enumera pormenorizadamente (:33-34). Pero si Derrida hace hincapié en el desordenamiento del tiempo, es gracias a la irrupción de ese fantasma que, dice, constantemente "asedia" cualquier "orden tranquilizador de los presentes". El fantasma disloca el tiempo, puesto que, dice Derrida, es siempre "Cuestión de repetición... No se pueden controlar sus idas y venidas porque empieza por regresar..." (Derrida, 1995: 25). Re-enter the Ghost. Hamlet, una y otra vez, cabrá mencionarlo, buscará “conjurar" al fantasma, en el doble sentido de "invocarlo", para después desterrarlo y expulsarlo en nombre de lo que vendrá a denominar como "justicia"; "...Ob cursed spight/ That ever I was borne to set it right!...". Este aspecto será uno de los puntos principales que interesarán 
a Derrida para permitirle ligar dicha lectura de Shakespeare con el tema de Marx.

${ }^{26}$ Cfr. nota 7.

${ }^{27}$ A lo que Derrida se está refiriendo aquí no es necesariamente a deshacernos de lo que habitualmente entendemos por "signo", en el sentido de la impresión de letras, señales tipográficas o de puntuación, etcétera en el proceso de escritura, sino a deconstruir la conceptualidad del concepto de "signo", sobre todo en la acepción semiológica de la lingüística estructural. Derrida dice, a propósito de su "proyecto" gramatológico: "Esto equivale, con todo rigor, a destruir el concepto de ‘signo' y toda su lógica” (Derrida, 1971: 12).

${ }^{28}$ (Derrida, 1977: 55). En este punto, Derrida se está refiriendo, como se puede ver, al texto hegeliano: a la imposibilidad de generar un momento de síntesis o resolución (reunión en una unidad, Aufhebung) de las diferencias. Con respecto a esto, y para citar los principales términos indecidibles que el mismo Derrida enuncia, tendríamos: "differánce", "gramma", "huella", "cala", "de-limitación”, "fármacon”, "suplemento", "bymen", "marca-marcha-márgen", entre otras; "...el movimiento de esas señales se transmite a toda la escritura y no puede encerrarse en una taxonomía acabada, y aún menos, en un léxico en tanto que tal..." (Derrida, 1997: 40). Derrida, a su vez, enuncia las "razones" por las que estos términos son irreductibles a la dialéctica especulativa: "...el fármacon no es ni el remedio, ni el veneno, ni el bien ni el mal, ni el adentro ni el afuera, ni la palabra ni la escritura; el suplemento no es ni un más ni un menos, ni un afuera ni el complemento de un adentro, ni un accidente, ni una ausencia, etc.; el bymen no es ni la confusión ni la distinción, ni la identidad ni la diferencia, ni la consumación ni la virginidad, ni el velo ni el desvelamiento, ni el adentro ni el afuera, etc.; el grama no es ni un significante ni un significado, ni un signo ni una cosa, ni una presencia ni una ausencia, ni una posición ni una negación, etc.; el espaciamiento, no es ni el espacio ni el tiempo [...] Ni/ ni, es a la vez o bien o bien; la marca también es el límite marginal, la mancha, etc..." (Derrida, 1977: 55).

${ }^{29}$ Derrida, una vez más (cfr. nota 17), asume que toma "en préstamo" del lenguaje de la metafísica y de la fenomenología trascendental ciertos términos que podrían delinear de algún modo, comprensiblemente, su exposición acerca de la différance (por "comodidad estratégica”). "...Para reproducir aquí dice-, análogamente y de manera provisional, un lenguaje fenomenológico y trascendental que se revelará enseguida inadecuado [es que] yo propongo llamar [a este movimiento], una 'superestructura originaria', 'archi-escritura' o 'archirastro'..." (Derrida, 1998b: 48-49) (El subrayado es nuestro). Sin embargo, esta caracterización no será del todo convencional ni, incluso, meramente provisional, dado que esta noción de "superestructura originaria" la utiliza en algunos otros textos ( $c f r$. sobre todo Derrida, 1977), y en parte, dado que la différance, dice, "es el juego que hace que haya efectos nominales, estructuras relativamente unitarias o atómicas que se llaman nombres, cadenas de sustituciones de nombres, y en las que, por ejemplo, el efecto nominal 'différance' es él mismo acarreado, llevado, reinscrito; como una falsa entrada o una falsa salida todavía es parte del juego, función de la estructura y del sistema...”. Derrida nombra así a la différance como aquello que permite la apertura de una determinada estructura o aquello que le subyace para ir más allá de los límites de su lógica, para cuestionar el carácter mismo de "estructura" y con ello, simultáneamente, para desaparecer en su condición de "superestructura".

${ }^{30}$ En términos muy generales ésta es la fórmula en la que consiste el llamado planteamiento de la "diferencia ontológica", uno de los conceptos centrales en la obra del pensador alemán. Heidegger expone esta cuestión en diversos escritos, sobre todo de su segunda época, pero fundamentalmente, para una revisión más detallada, se remite a Identidad y diferencia (Identität und Differenz, 1957), particularmente el ensayo "La constitución onto-teo-lógica de la metafísica” (Heidegger, 1990: 67-123).

${ }^{31}$ Ligando esto con una frase contenida en un ensayo de 1963 titulado "Fuerza y significación" (en La escritura y la diferencia), la relación podría tornarse más clara: "Si es necesario decir [como eventualmente dijera Nietzsche] que 'todo no es más que Dionisos', es también necesario saber que, como la fuerza pura, Dionisos es atormentado en todas partes por la diferencia..."32. Así, si "Dionisos" es el nombre mediante el que Nietzsche concibe su filosofía, su estilo, su escritura, su vida misma, y si seguimos la lectura de la frase indicada "Todo no es más que Dionisos...”, no es difícil ver que para Derrida -y en general, para gran parte del pensamiento filosófico francés del siglo XX-, Nietzsche no sería, en cierto sentido, "más que diferencia", relación de la fuerza con la fuerza, afirmación pura y afirmación desdoblada de la vida, en suma, voluntad de poder (Wille zurMacht); pero entendida ésta no como una voluntad de "querer" el poder, esto es, como voluntad de dominio, sino como un afán por ir "hacia" el poder, pero poder de querer cada vez más la capacidad de seguir queriendo el "poder" de ir más allá de sí mismo; no contentar a la propia voluntad con cada nivel de poder 
alcanzado, inscribiéndola así en una cadena de constantes autosuperaciones. En este sentido hay efectivamente un paralelismo entre esa voluntad que está constantemente en persecución de sí misma, transgrediendo sus propios límites, y la imagen derridiana de la "huella", que se desplaza del signo por el efecto espacio-temporizador de la différance.

\section{Bibliografía}

Birnbau, Jean, 2004, Le Monde, 19 agosto, www.personales.ciudad.com.ar

Cragnolini, Mónica, "Para una «melancología» de la alteridad. Diseminaciones derridinas en el pensamiento nietzscheano", en www.nietzscheana.ar

-, "Un mundo de fantasmas y huellas sin origen", www.nietzscheana.ar

Culler, Jonathan, 1992, Sobre la deconstrucción, Cátedra, Madrid.

Dalmasso, Gianfranco, 1978, El lugar de la ideología. Por una lectura no burguesa de: Marx, Freud, Althusser, Tel quel, Derrida y el neomarxismo, Editorial Zero zyx, Madrid.

Deleuze, Gilles, 1999, Repetición y diferencia, Anagrama, Barcelona.

Deleuze, G. y Parnet, C., 1997, Diálogos, Pre-Textos, Valencia.

De Peretti, Cristina, 1989, Jacques Derrida. Texto y deconstrucción, Anthropos, Barcelona.

De Peretti, Cristina, y Francisco Vidarte, 2002, "Nietzsche siguiendo a Derrida", en Nietzsche 100 años después, Pretextos, Valencia.

Derrida, Jacques, 1971, De la gramatología, Ed. S. XXI, Buenos Aires.

—, 1997, "Carta a un amigo japonés", en El tiempo de una tesis: Deconstrucción e implicaciones conceptuales, Proyecto A Ediciones, Barcelona.

—, 1995, Espectros de Marx Trotta, Madrid.

—, 1997, La diseminación, Editorial Fundamentos, Madrid.

—, 1998a "'La estructura, el signo y el juego en el discurso de las ciencias humanas", en La escritura y la diferencia, Anthropos, Barcelona.
-, "Fuerza y significación", La escritura y la diferencia, Anthropos, Barcelona.

_, 1998b, "La Différance”, en Márgenes de la filosofía, Cátedra, Madrid.

—, 1998c, "Tímpano", en Márgenes de la filosofía, Cátedra, Madrid.

—, 1996, "Interpretar las firmas: Nietzsche/Heidegger", en Nietzsche. Politicas del nombre propio, Trotta, Madrid.

—, 1989, "Entrevista con Jacques Derrida", en Política y sociedad, Tecnos, Madrid.

—, 1977, Posiciones. Entrevista con Jacques Derrida, Pre-Textos, Valencia.

Descombes, Vincent, 1995, Lo mismo y lo otro, Cátedra, Madrid.

Foucault, Michel, 1999, Theatrum philosophicum, Anagrama, Barcelona.

Heidegger, Martin, 2000, "La sentencia de Anaximandro", en Caminos de bosque, Alianza Editorial, Madrid.

—, 2001, "Superación de la metafísica", en Conferencias y artículos, Ediciones del Serbal, Barcelona.

—, 1990, "La constitución onto-teo-lógica de la metafísica", en Identidady diferencia, Anthropos, Barcelona.

Hopenhayn, Martin, 1997, Después del nihilismo. De Nietzssche a Foucault, Editorial Andrés Bello, Santiago de Chile.

Martínez de la Escalera, Ana María, 2004, Interpretar en filosofía. Un estudio contemporáneo. IIFL, UNAM, México.

Nietzsche, Friedrich, 1998, El ocaso de los ídolos, Tusquets, Barcelona.

—, 1973, En torno a la voluntad de poder (selección de textos), Península, Barcelona.

Norris, Christopher, 1982, "From voice to text: Derrida's critique of philosophy"; "Jacques Derrida: language against itself", en Deconstruction: Theory and Practice, Routledge ed., London.

Quevedo, Amalia, 2001, De Foucault a Derrida, Ediciones de Universidad de Navarra, Navarra.

Saussure, Ferdinand de, 1975, Curso de lingüistica general, Ediciones Losada, Buenos Aires.

Vattimo, Gianni, 1997, Ética de la interpretación, Paidós, Barcelona.

- 1998, Las aventuras de la diferencia, Península, Barcelona. 